\title{
RELIABILITY OF MANDIBULAR CANINE MATURATION STAGES IN PREDICTING PUBERTAL GROWTH SPURT IN A SAMPLE OF EGYPTIAN ORTHODONTIC PATIENTS
}

\author{
Mohammed Hassan Zaghloul*, Al-Dany Atwa Mohammed**, Khalid Farouk Abd Allah***
}

\begin{abstract}
Objective: Investigating the reliability of mandibular canine maturation stages in predicting pubertal growth spurt in a sample of Egyptian orthodontic patients.

Subjects and Methods: A retrospective, cross-sectional study was carried out on the radiographic records (left lateral cephalometric, panoramic, and left hand and wrist x-rays) obtained from 250 patients who were attending private clinics on Delta area, Egypt. The age of the patients ranged from 7 to 18 years. Mandibular canine calcification stages (MCC) were assessed according to Demirjian's method for dental maturity assessment. Skeletal maturity was assessed by the ossification stages of the middle phalanx of the third finger (MP3) using Hagg and Taranger method, and the cervical vertebrae maturation index (CVMI) was evaluated using Hassel and Farman method.
\end{abstract}

Results: Chi-square tests have shown highly significant associations between the mandibular canine calcification stages (MCC) and both CVMI and MP3 maturation stages $(\mathrm{p}<0.001)$. MCC stage F had shown a moderate correlation with MP3 FG and CVMI 2 that corresponded to the onset of pubertal growth.

Conclusions: MCC stage F can be used for prediction of the onset of pubertal growth, while the prediction of the peak or the post-peak periods using MCC method may be unreliable.

Keywords: Pubertal growth, MP3 stages, CVMI stages, MCC stages.

\section{INTRODUCTION}

Defining the correct timing of dentofacial growth and development is an essential aspect of orthodontic diagnosis and treatment planning, as this would clarify the proper timing for orthopedic intervention. Utilizing appropriate growth changes and prevention of undesirable ones constitutes the general concept of orthopedic treatment. Therefore, it would be useful to study in detail the growth and development of the different parts of the craniofacial structures ${ }^{1}$.

The maturational status of an individual can be best evaluated relative to different stages of physiologic maturity rather than evaluating it with chronologic age because the latter is not a reliable indicator ${ }^{2}$. Physiologic maturity is best estimated by the maturation of one or more tissue systems, such as somatic include (height ${ }^{3-5}$, weight ${ }^{6}$ ), sexual ${ }^{7}$, skeletal include (hand-wrist maturity ${ }^{4,8-13}$, cervical vertebrae ${ }^{14-17}$ ), dental maturity ${ }^{18-21}$ and recently introduced biomarkers ${ }^{22-29}$.

Lately, in an attempt to further reducing the radiation dose, the dental calcification stages, as seen on routinely taken panoramic radiograph has been used to assess the level of skeletal maturation. Some studies have shown a strong correlation between

\footnotetext{
* Master Degree Student, Department of Orthodontics, Faculty of Dental Medicine, Boys, Cairo, Al-Azhar University.

** Professor, Department of Orthodontics, Faculty of Dental Medicine, Boys, Cairo, Al-Azhar University.

*** Lecturer, Department of Orthodontics, Faculty of Dental Medicine, Boys, Cairo, Al-Azhar University.
} 
calcification stages of various mandibular teeth particularly the mandibular canine and the skeletal maturity ${ }^{30-43}$, while others have refuted this claim ${ }^{44-48}$. Because of this controversy and the well-established racial variation in the stages of dental calcification $^{30,33,42,49-51}$, the present study was undertaken to investigate the reliability of mandibular canine maturation stages in predicting pubertal growth spurt in a sample of Egyptian orthodontic patients.

\section{MATERIALS AND METHODS}

This retrospective, cross-sectional study was carried out on 750 radiographs taken from the records of 250 subjects; 139 females and 111 males, three radiographs (left lateral cephalometric, panorama and left hand and wrist) were analyzed for each subject.

The sample size calculation was based on the power analysis using pubertal spurt age as the primary outcome. The age was selected between 7 and 18 years.

Data collected for every subject were; the name, gender, date of birth, and the date when the x-rays were taken. Chronological age at the time when the $\mathrm{x}$-ray was taken was determined by the date of birth recorded on the $\mathrm{x}$-rays. The mean age was $11.6+2.32$ $\mathrm{y}$ for males and $12+2.9 \mathrm{y}$ for females. The second supervisor did the anonymization of the radiographs by removing the personal details of each patient and replacing them by a code number.

\section{Tracing}

Tracing was performed by using .003 " acetate tracing paper and $4 \mathrm{Hb}$ pencil, in a darkened room with a radiographic illuminator to ensure contrast enhancement of the bone and dental structures ${ }^{52}$.

\section{Dental maturity assessment}

The calcification stages of the left mandibular canine were assessed according to Demirjian's method of dental maturity assessment. Mandibular left canine has been rated according to developmental criteria (amount of dentinal deposit, shape change of pulp chamber, etc.) rather than changes in size. Eight stages, A to $\mathrm{H}$, have been defined in the original method. However, in this study, only five stages ( $\mathrm{D}$ to $\mathrm{H}$ ) were assessed due to their relevance with the circumpubertal growth phase ${ }^{20}$ (table 1).

TABLE (1): showing the calcification stages of left mandibular canine according to Demirjian's method ${ }^{20}$ :

\section{Stage D.}

(1) Crown formation is complete down to CEJ.

(2) Superior border of pulp chamber is curved and being concave towards the cervical region.

(3) Beginning of root formation in the form of a spicule.

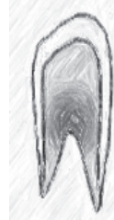

\section{Stage E.}

(1) The walls of the pulp chamber form straight lines.

(2) The root length is less than the crown height.

\section{Stage F.}

(1) The walls of the pulp chamber form a more or less isosceles triangle, with the apex ending in a funnel shape.

(2) The root length is equal to or greater than the crown height.

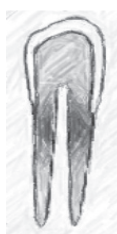




\section{Stage G.}

(1) The walls of the root canal are parallel and its apical end is still partially open.

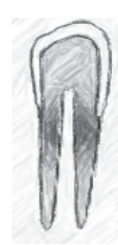

\section{Stage $\mathbf{H}$.}

(1) The apical end of the root canal is completely closed.

(2)The periodontal membrane has a uniform width around the root and the apex.

\section{Skeletal maturity assessment:}

Middle phalanx of third finger maturation stages (MP3):

MP3 Ossification Stages were evaluated according to Hagg and Taranger Method ${ }^{7}$ which is summarized in (table 2).

TABLE (2): MP3 Ossification Stages according to Hagg and Taranger Method ${ }^{7}$

\section{MP3-F:}

Epiphysis is as wide as metaphysis.

Occurs before onset of PHV.

More than $80 \%$ of pubertal growth remaining.

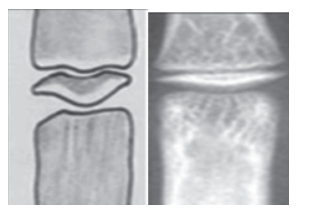

\section{MP3-FG:}

Epiphysis is as wide as metaphysis.

Distinct medial and /or lateral border of epiphysis forming a line of demarcation at right angle to distal border.

Indicates the accelerating slope of pubertal growth spurt.

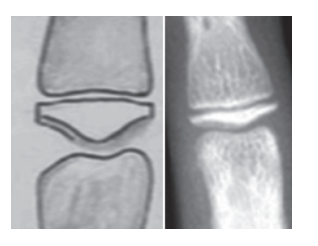

MP3-G:

The sides of epiphysis thickened and cap its metaphysis forming a sharp edge at one or both sides.

Corresponds to the peak of pubertal growth.

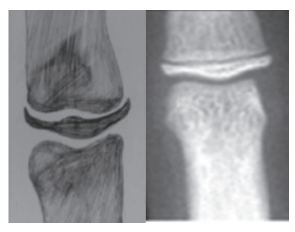

\section{MP3-H:}

Characterized by beginning of fusion epiphysis and metaphysis. Indicates the decelerating slope but before the end of growth spurt.

\section{MP3-I}

Characterized by completion of fusion of epiphysis and metaphysis. This is attained at end of growth spurt.
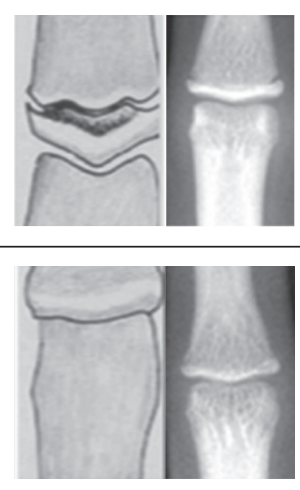


\section{Cervical vertebrae maturational stage (CVMs):}

The cervical vertebrae maturity indicator (CVMI) was evaluated on the lateral cephalogram by using the method proposed by Hassel and Farman ${ }^{15}$ (table 3).

TABLE (3) The cervical vertebrae maturity indicator (CVMI) using Hassel and Farman method: ${ }^{15}$

CVMI 1 (Initiation):

The inferior borders of $\mathrm{C} 2, \mathrm{C} 3$, and $\mathrm{C} 4$ are flat. The vertebrae are wedge shaped, and the superior vertebral borders are tapered from posterior to anterior. About $80 \%-100 \%$ of adolescent growth remains. cs 1

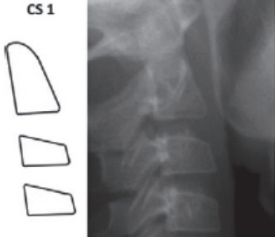

CVMI 2 (Acceleration):

Concavities develop on the inferior borders of $\mathrm{C} 2$ and $\mathrm{C} 3$. The inferior border of $\mathrm{C} 4$ is flat. The bodies of $\mathrm{C} 3$ and $\mathrm{C} 4$ are nearly rectangular in shape. About $65 \%$ $85 \%$ of adolescent growth remains.

\section{CVMI 3 (Transition):}

Distinct concavities are seen on the inferior borders of $\mathrm{C} 2$ and $\mathrm{C} 3$. A concavity is beginning to develop on the inferior border of $\mathrm{C} 4$. The bodies of $\mathrm{C} 3$ and $\mathrm{C} 4$ are rectangular in shape. About $25 \%-65 \%$ of adolescent growth remains.

\section{CVMI 4 (Deceleration):}

Distinct concavities are seen on the inferior borders of $\mathrm{C} 2, \mathrm{C} 3$, and $\mathrm{C} 4$. The vertebral bodies of $\mathrm{C} 3$ and $\mathrm{C} 4$ are becoming squarer in shape. About 10\%-25\% of adolescent growth remains.

\section{CVMI 5 (Maturation):}

More accentuated concavities are seen on the inferior borders of $\mathrm{C} 2, \mathrm{C} 3$, and $\mathrm{C} 4$. The bodies of $\mathrm{C} 3$ and $\mathrm{C} 4$ are square or nearly square in shape. About $5 \%-10 \%$ of adolescent growth remains.

\section{CVMI 6 (Completion):}

Deep concavities are seen on the inferior borders of C2, C3, and C4. The bodies of $\mathrm{C} 3$ and $\mathrm{C} 4$ are square or have greater vertical than horizontal dimension. Little or no adolescent growth remains.

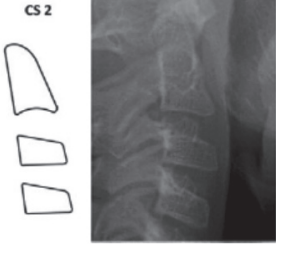

cs 3

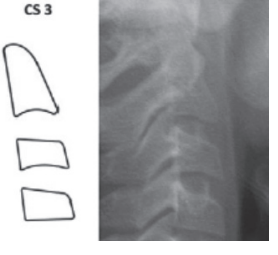

cs 4
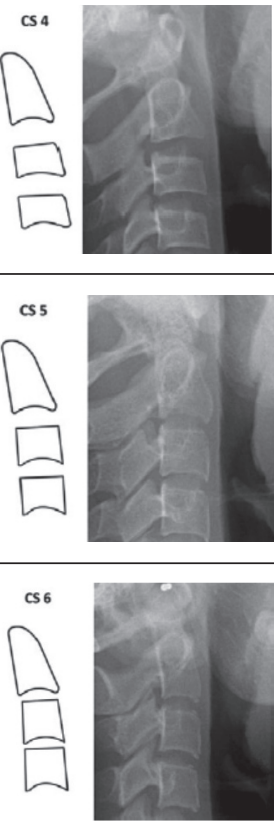


\section{Reliability of measurements:}

Randomly selected 249 radiographs for 83 patients (30\% of the total sample) including an equal number of panoramic, lateral cephalometric and hand-wrist radiographs were recorded by the second supervisor and re-assessed blindly by the same investigator. The data from these 249 radiographs were statistically compared with the data from the total sample to assess the reliability of measurements.

\section{RESULTS}

In the present study, Chi-square tests have shown highly significant associations between the mandibular canine calcification stages (MCC) and both CVMI and MP3 maturation stages in females and males $(\mathrm{p}<0.001)$ as shown in (tables 4,5$)$ respectively.

TABLE (4): Frequencies, percentages and results of Chi-square test for the association between MCC and CVM stages in females and males:

\begin{tabular}{|c|c|c|c|c|c|c|c|c|c|c|c|c|c|c|}
\hline \multirow{3}{*}{ تُّن } & \multirow[b]{3}{*}{ MCC stage } & \multicolumn{12}{|c|}{ CVM stage } & \multirow{3}{*}{$P$-value } \\
\hline & & \multicolumn{2}{|c|}{ Stage 1} & \multicolumn{2}{|c|}{ Stage 2} & \multicolumn{2}{|c|}{ Stage 3} & \multicolumn{2}{|c|}{ Stage 4} & \multicolumn{2}{|c|}{ Stage 5} & \multicolumn{2}{|c|}{ Stage 6} & \\
\hline & & $\mathbf{n}$ & $\%$ & $\mathbf{n}$ & $\%$ & $\mathbf{n}$ & $\%$ & $\mathbf{n}$ & $\%$ & $\mathbf{n}$ & $\%$ & $\mathbf{n}$ & $\%$ & \\
\hline \multirow{5}{*}{ } & Stage D & 1 & 2.6 & 0 & 0 & 0 & 0 & 0 & 0 & 0 & 0 & 0 & 0 & \multirow{5}{*}{$<0.001 *$} \\
\hline & Stage E & 22 & 56.4 & 2 & 13.3 & 0 & 0 & 0 & 0 & 0 & 0 & 0 & 0 & \\
\hline & Stage F & 13 & 33.3 & 8 & 53.3 & 4 & 33.3 & 2 & 13.3 & 0 & 0 & 0 & 0 & \\
\hline & Stage $\mathbf{G}$ & 2 & 5.1 & 4 & 26.7 & 5 & 41.7 & 5 & 33.3 & 0 & 0 & 0 & 0 & \\
\hline & Stage $\mathbf{H}$ & 1 & 2.6 & 1 & 6.7 & 3 & 25 & 8 & 53.3 & 14 & 100 & 44 & 100 & \\
\hline \multirow{5}{*}{$\frac{0}{\sum}$} & Stage D & 3 & 7.5 & 0 & 0 & 0 & 0 & 0 & 0 & 0 & 0 & 0 & 0 & \multirow{5}{*}{$<0.001 *$} \\
\hline & Stage E & 19 & 47.5 & 11 & 27.5 & 0 & 0 & 0 & 0 & 0 & 0 & 0 & 0 & \\
\hline & Stage F & 13 & 32.5 & 21 & 52.5 & 1 & 9.1 & 2 & 25 & 0 & 0 & 0 & 0 & \\
\hline & Stage G & 4 & 10 & 6 & 15 & 3 & 27.3 & 3 & 37.5 & 0 & 0 & 0 & 0 & \\
\hline & Stage $\mathbf{H}$ & 1 & 2.5 & 2 & 5 & 7 & 63.6 & 3 & 37.5 & 7 & 100 & 5 & 100 & \\
\hline
\end{tabular}

$n:$ number, *: Significant at $P \leq 0.05$

TABLE (5): Frequencies, percentages and results of Chi-square test for the association between MCC and MP3 stages in females and males:

\begin{tabular}{|c|c|c|c|c|c|c|c|c|c|c|c|c|}
\hline \multirow{3}{*}{$\begin{array}{l}\Omega \\
\stackrel{2}{9}\end{array}$} & \multirow[b]{3}{*}{ MCC stage } & \multicolumn{10}{|c|}{ MP3 stage } & \multirow{3}{*}{$P$-value } \\
\hline & & \multicolumn{2}{|c|}{ Stage F } & \multicolumn{2}{|c|}{ Stage FG } & \multicolumn{2}{|c|}{ Stage G } & \multicolumn{2}{|c|}{ Stage $H$} & \multicolumn{2}{|c|}{ Stage I } & \\
\hline & & $\mathbf{n}$ & $\%$ & $\mathbf{n}$ & $\%$ & $\mathbf{n}$ & $\%$ & $\mathbf{n}$ & $\%$ & $\mathbf{n}$ & $\%$ & \\
\hline \multirow{5}{*}{ 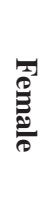 } & Stage D & 1 & 3.3 & 0 & 0 & 0 & 0 & 0 & 0 & 0 & 0 & \multirow{5}{*}{$<0.001^{*}$} \\
\hline & Stage E & 18 & 60 & 6 & 27.3 & 0 & 0 & 0 & 0 & 0 & 0 & \\
\hline & Stage F & 9 & 30 & 11 & 50 & 7 & 23.3 & 0 & 0 & 0 & 0 & \\
\hline & Stage G & 1 & 3.3 & 4 & 18.2 & 10 & 33.3 & 1 & 7.7 & 0 & 0 & \\
\hline & Stage H & 1 & 3.3 & 1 & 4.5 & 13 & 43.3 & 12 & 92.3 & 44 & 100 & \\
\hline \multirow{5}{*}{$\frac{3}{\frac{3}{2}}$} & Stage D & 3 & 5.3 & 0 & 0 & 0 & 0 & 0 & 0 & 0 & 0 & \multirow{5}{*}{$<0.001^{*}$} \\
\hline & Stage E & 27 & 47.4 & 3 & 12 & 0 & 0 & 0 & 0 & 0 & 0 & \\
\hline & Stage F & 22 & 38.6 & 12 & 48 & 3 & 16.7 & 0 & 0 & 0 & 0 & \\
\hline & Stage G & 3 & 5.3 & 6 & 24 & 7 & 38.9 & 0 & 0 & 0 & 0 & \\
\hline & Stage $\mathbf{H}$ & 2 & 3.5 & 4 & 16 & 8 & 44.4 & 7 & 100 & 4 & 100 & \\
\hline
\end{tabular}

$n:$ number $*$ : Significant at $P \leq 0.05$ 


\section{DISCUSSION}

The most popular methods for assessment the pubertal growth spurt are the skeletal maturity indicators such as hand- wrist (HWMI), cervical vertebrae (CVMI) and middle phalanx of third finger

(MP3) ${ }^{49}$. In order to reduce the number of radiographic exposure and to provide a more easy method for evaluating physiologic maturity,Demirjian introduced a method based upon assessment of dental maturation through the use of panoramic radiograph ${ }^{20}$. The results of the present study have indicated that females mature earlier than males; therefore, it is very important clinically, to initiate functional and orthopedic treatment earlier in females than males. This finding is in agreement with Hunter ${ }^{3}$, Hagg and Taranger ${ }^{7}$, Chen et al ${ }^{31}$, RozyloKalinowska et al ${ }^{36}$, Bagherpour et al ${ }^{39}$, Yadav et $\mathrm{al}^{43}$, Howell ${ }^{53}$ and Nemati et al ${ }^{54}$.

According to the results of the current study, growth modification is preferred to be done between 9.67 and 12.85 years in females and 12.34 to 14.74 years in males because this represents the active period of growth between the pre-peak (MP3-FG) and the onset of post-peak (MP3-H) stages. This finding is in accordance with the study done by Abd Elsayed et al ${ }^{55}$ which concluded that the pre-peak stage (MP3-FG) was reached at 12.85 years while the post-peak stage (MP3-H) started at 14.6 years in Egyptian Cairo adolescent males.

At CVMI stage 3, 63.6\% of males showed MCC stage $\mathrm{H}$ while $41.7 \%$ of females showed MCC stage $\mathrm{G}$, therefore male subjects had a more advanced trend in tooth calcification than females. These results are in accordance with previous studies ${ }^{33,49}$.

There was a significant correlation between the mandibular canine calcification (MCC) stage F and both CVMI 2, MP3 FG stages. These stages represent the pre-peak or the onset of the accelerating phase of growth in both males and females. MCC stage $\mathrm{H}$ was found to correspond to the peak and postpeak periods of pubertal growth in both genders when relating to MP3 staging. When relating to
CVMI stages, males with MCC stage $\mathrm{H}$ were found to correspond to peak and post-peak periods, while female subjects showed more tendencies toward MCC stage G (peak of pubertal growth).

From these results, one can conclude that MCC stage F can be used for prediction of the onset of pubertal growth, while the prediction of the peak or the post-peak periods using MCC method may be unreliable.

Clinically, MCC stage F is considered as the best time for growth modification because it represents the onset of accelerating growth and about $65 \%$ $85 \%$ of adolescent growth remains. But patients who showed MCC stage $\mathrm{H}$ are most probably lie in post-peak phases, where a little percent of growth remaining, therefore, for growth modification to be undertaken, further investigations are recommended to accurately assess the pubertal growth phase. These results are in agreement with Coutinho ${ }^{30}$, RóżyłoKalinowska et al ${ }^{36}$, Perinetti et al ${ }^{37}$ and Goyal et $\mathrm{a}^{40}$, who reported that MCC stage F correspond to the onset of accelerating phase of pubertal growth.

\section{CONCLUSION}

Mandibular canine calcification stages can be clinically used as a maturity indicator of the pubertal growth, only during the pre-peak period of pubertal growth. MCC stage F is the best time for growth modification using orthopedic or functional appliances. Females mature earlier than males by about two years.

MCC staging method is simple, economical and eliminates the need for additional $\mathrm{x}$-rays; in addition, it is available in most orthodontic offices.

\section{RECOMMENDATION}

Further study is recommended on a larger sample from different regions of Egypt to corroborate the findings. Clinically, MCC staging is recommended to be routinely evaluated on the periapical or panoramic radiograph as a first diagnostic level of the pubertal status of a patient. 


\section{REFERENCES}

1. Arat M, Köklü A, Özdiler E, Rübendüz M, Erdoğan B. Craniofacial growth and skeletal maturation: A mixed longitudinal study. Eur J Orthod, 2001; 23:355-361.

2. Korde S, Daigavane P, Shrivastav S. Skeletal Maturity Indicators - Review Article. Int J Sci Res, 2015; 6:361-370.

3. Hunter C. The correlation of facial growth with body height and skeletal maturation at adolescence. Angle Orthod, 1966; 36:44-54.

4. Björk A, Helm S. Prediction of the age of maximum puberal growth in body height. Angle Orthod, 1967; 37:134-143.

5. Pancherz H, Hägg U. Dentofacial orthopedics in relation to somatic maturation: an analysis of 70 consecutive cases treated with the Herbst appliance. Am J Orthod, 1985; 88:273-287.

6. Green L. The interrelationships among height, weight and chronological, dental and skeletal ages. Angle Orthod, 1961; 31:189-193.

7. Hägg U, Taranger J. Maturation indicators and the pubertal growth spurt. Am J Orthod, 1982; 82:299-309.

8. Hägg U, Taranger J. Skeletal stages of the hand and wrist as indicators of the pubertal growth spurt. Acta Odontol Scand, 1980; 38:187-200.

9. Flores-Mir C, Nebbe B, Major P. Use of skeletal maturation based on hand-wrist radiographic analysis as a predictor of facial growth: a systematic review. Angle Orthod, 2004; 74:118-124.

10. Fishman L. Radiographic evaluation of skeletal maturation: a clinically oriented method based on hand-wrist films. Angle Orthod, 1982; 52:88-112.

11. Pyle S. Skeletal maturation: hand-wrist radiographic assessment. Bolt Stand Dentofac Dev growth St Louis CV Mosby, 1975; 45-79.

12. Bolt R. Atlas of Skeletal Maturation (Hand). Am J Pub Health Nat Health, 1938; 28 (9):1130-30.

13. Tanner J, Whitehouse R, Marshall W. Assessment of skeletal maturity and prediction of adult height (TW2 method). Academic Pr, 1983;1-110.

14. Baccetti T, Franchi L, McNamara J. The cervical vertebral maturation (CVM) method for the assessment of optimal treatment timing in dentofacial orthopedics. Seminar Orthod, 2005; 11:119-129.

15. Hassel B, Farman A. Skeletal maturation evaluation using cervical vertebrae. Am J Orthod Dentofac Orthop, 1995; 107:58-66.
16. Lampalski D. Skeletal age assessment utilizing cervical vertebrae. MD Sci Thesis Uni Pittsburgh, 1972.

17. Baccetti T, Franchi L, McNamara J. An improved version of the cervical vertebral maturation (CVM) method for the assessment of mandibular growth. Angle Orthod, 2002; 72:316-323.

18. Demisch A, Wartmann P. Calcification of the mandibular third molar and its relation to skeletal and chronological age in children. Child Dev, 1956; 459-473.

19. Nolla C. The development of the permanent teeth. J Dent Child, 1960, 27: 254-263.

20. Demirjian A, Goldstein H, Tanner J. A new system of dental age assessment. Hum Biol, 1973; 211-227.

21. Demirjian A, Goldstein H. New systems for dental maturity based on seven and four teeth. Ann Hum Biol, 1976; 3:411-421.

22. Himes J, Huang Z, Haas J, Rivera R, Pineda O. Serum alkaline phosphatase activity and skeletal maturation in Guatemalan adolescents. Ann Hum Biol, 1993; 20:39-46.

23. Perinetti G, Baccetti T, Contardo L, Di Lenarda R. Gingival crevicular fluid alkaline phosphatase activity as a noninvasive biomarker of skeletal maturation. Orthod Craniofac Res, 2011; 14:44-50.

24. Argente J, Barrios V, Pozo J, Munoz M, Hervas F, et al. Normative data for insulin-like growth factors (IGFs), IGF-binding proteins, and growth hormone-binding protein in a healthy Spanish pediatric population: age-and sex-related changes. J Clin Endocrinol Metab, 1993; 77:1522-28.

25. Delmas P. Biochemical markers of bone turnover. J Bone Miner Res, 1993; 8:s549-555.

26. Ishaq R, Soliman S, Foda M, Fayed M. Insulin-like growth factor I: a biologic maturation indicator. Am J Orthod Dentofac Orthop, 2012; 142:654-661.

27. Srinivasan B, Premkumar S. Assessment of serum dehydroepiandrosterone sulphate in subjects during the prepubertal, pubertal, and adult stages of skeletal maturation. Eur J Orthod, 2011; 34:447-451.

28. Gupta S, Jain S, Gupta P, Deoskar A. Determining skeletal maturation using insulin-like growth factor I (IGF-I) test. Prog Orthod, 2012; 13:288-295.

29. Perinetti G, Baccetti T, Leonardo B, Lenarda R, Contardo L. Dentition phase and chronological age in relation to gingival crevicular fluid alkaline phosphatase activity in growing subjects. Prog Orthod, 2011; 12:100-106. 
30. Coutinho S, Buschang P, Miranda F. Relationships between mandibular canine calcification stages and skeletal maturity. Am J Orthod Dentofac Orthop, 1993; 104:262-268.

31. Chen J, Hu H, Guo J, Liu Z, Liu R, et al. Correlation between dental maturity and cervical vertebral maturity. Oral Sur Oral Med Oral Pathol Oral Radiol Endodont, 2010; 110:777-783.

32. Khan R, Ijaz A. Correlation of Dental Calcification and Skeletal Maturity Indicators. Ann King Edward Med Univ, 2011; 17:22.

33. Chertkow S. Tooth mineralization as an indicator of the pubertal growth spurt. Am J Orthod, 1980; 77:79-91.

34. Lü Y. Relationships between mandibular canine calcification stages and skeletal maturity. Chinese J Stomatol, 1999; 34:40-42.

35. Nayak R, Nayak U, Hegde G. Assessment of growth using mandibular canine calcification stages and its correlation with modified MP3 stages. Int J Clin Pediatr Dent, 2010; 3:27.

36. Różyło-Kalinowska I, Kolasa-Rączka A, Kalinowski P. Relationship between dental age according to Demirjian and cervical vertebrae maturity in Polish children. Eur J Orthod, 2010; 33:75-83.

37. Perinetti G, Contardo L, Gabrieli P, Baccetti T, Lenarda R. Diagnostic performance of dental maturity for identification of skeletal maturation phase. Eur J Orthod, 2011; 34:487-492.

38. Malik P, Rana V, Rehani U. To evaluate the relationship between mandibular canine calcification stages and skeletal age. Int J Clin Pediatr Dent, 2012; 5:14.

39. Bagherpour A, Pousti M, Adelianfar E. Hand skeletal maturity and its correlation with mandibular dental development. J Clin Exp Dent, 2014; 6:e275.

40. Goyal S, Goyal S, Gugnani N. Assessment of skeletal maturity using the permanent mandibular canine calcification stages. J Orthod Res, 2014; 2:11.

41. Hegde G, Hegde N, Anil Kumar K. A new system for assessment of growth using mandibular canine calcification stages and its correlation with modified MP3 stages. J Pharm Bioallied Sci, 2014; 6:S58.

42. Vijayalakshmi G. Mandibular canine calcification as skeletal maturity indicator. World J Dent, 2017; 8:119-128.

43. Yadav V, Loomba A, Autar R. A comparative evaluation of dental calcification stages and skeletal maturity indicators in North-Indian children. Natl J Maxillofac Surg, 2017; 8:26

44. Tanner J. Growth at adolescence. Spr Field, III, 1962; 1: 592.

45. Garn S, Lewis A, Bonné B. Third molar formation and its development course. Angle Orthod, 1962; 32:270-279.

46. Lewis A, Garn S. The relationship between tooth formation and other maturational factors. Angle Orthod, 1960; 30:70-77.

47. Abdel-Kader H. Pubertal growth spurt: approach and assessment among a sample of Saudi population. A D J, 1994; 9: 255-262.

48. Divyashree R, Dinesh M, Amarnath B. Reliability of permanent mandibular canine calcification as an indicator of skeletal maturity in Karnataka population. World J Dent, 2010; 1:7-11.

49. Krailassiri S, Anuwongnukroh N, Dechkunakorn S. Relationships between dental calcification stages and skeletal maturity indicators in Thai individuals. Angle Orthod, 2002; 72:155-166.

50. Uysal T, Sari Z, Ramoglu S, Basciftci F. Relationships between dental and skeletal maturity in Turkish subjects. Angle Orthod, 2004; 74:657-664.

51. Tafakhori Z, Shokrizadeh M, Fathollahi M. Relationship between Dental Development and Cervical Vertebrae Development Assessed Using Radiography in an Iranian Population. J Dento maxillofac Radiol Pathol Surg, 2016; 5: $17-23$

52. Rasool G, Bashir U, Kundi I. Comparative evaluation between cervical vertebrae and hand-wrist maturation for assessment of skeletal maturity orthodontic patients. Pakistan Oral Dent J, 2010; 30.

53. Howell J. A study into the relationship between dental development and cervical vertebral maturation in UK subjects. PhD diss, Uni of Birmingham, 2016.

54. Nemati S, AZIMI F, Rouhi M, Tafakhori Z. The Relationship between Dental Maturity based on Demirjian's Method and Cervical Vertebrae Maturation Stages in Guilan patients. 3DJ, 2017;6:1-9.

55. Abd Elsayed F, Kharsa K, Soliman S. Assessment of pubertal growth spurt in Egyptian adolescents using middle phalanx of the middle finger (MP3) in Cairo governorate : A cross sectional study. Egy dent j, 2015; 61 . 